\title{
A COMPARISON OF TRADING MODELS USED FOR CALCULATING AGGREGATE DAMAGES IN SECURITIES LITIGATION
}

\author{
MiCHAEL BARCLAY* AND FRANK C. TORCHIO**
}

\section{INTRODUCTION}

For approximately two decades, the General Trading Model ("GTM") has been used in securities litigation to estimate the number of shares damaged by alleged fraudulent misrepresentations by defendants. The GTM estimates the fraction of in-and-out trading volume and the fraction of retained volume. "Inand-out volume" refers to shares bought and sold within the class period; "retained volume" refers to shares purchased and held through the final disclosure that reveals the fraud. This is typically the last day of the class period. Estimates of the number of damaged shares from the GTM have been used in conjunction with a theory of true value (or conversely, artificial inflation) for the security to estimate aggregate monetary damages. ${ }^{1}$

Over the years, variations of the GTM predicated on different assumptions and/or parameters have been developed. The variations include single-trader models, such as the proportional and accelerated trading models, and multitrader models. ${ }^{2}$ This article compares the results of these models and critically evaluates the conclusions reached in previously published research.

This article demonstrates that results from the proportional single-trader model, GTM (1x), are consistent with the results of multi-trader GTMs when appropriate assumptions and parameters are used. No evidence was found to reject the GTM (1x) as a scientific method to estimate the number of damaged shares in securities litigation.

Copyright (C) 2001 by Michael Barclay and Frank C. Torchio

This article is also available at http://www.law.duke.edu/journals/64LCPBarclay.

* Alumni Distinguished Professor of Finance and Finance Area Coordinator, William E. Simon Graduate School of Business Administration, University of Rochester.

** President, Forensic Economics, Inc., a firm that consults in securities litigation cases and complex business disputes.

1. For example, Forensic Economics used the GTM in conjunction with a theory of true value to provide damage estimates of $\$ 8.5$ billion in the Cendant securities litigation, the largest class action securities litigation settlement in history. See generally In re Cendant Corp. Sec. Litig., 109 F. Supp. 2d 285 (D.N.J. 2000).

2. Virtually every securities litigation case in which aggregate damages are estimated relies on a version of the GTM for the number of shares damaged and the damage theory for the amount of artificial inflation. See id. 


\section{BACKGROUND}

In securities litigation, damages arise when defendants make false or misleading statements that artificially inflate the stock price. ${ }^{3}$ If an investor purchases the stock at this artificially inflated price, and the price later declines when the fraud is revealed, the investor will suffer damages from paying too much for the stock. In general, damages per share are calculated as the artificial inflation when the shares were purchased minus the artificial inflation when the shares were sold. For example, shares purchased when the stock price was artificially inflated and held through a disclosure that reveals the fraud typically are considered to be damaged. Shares purchased and then sold before any revelation of the fraud, however, are typically not considered to be damaged because these shares were passed on before any deflation in value.

Experts on damages in securities class actions generally do not have access to the trading records of individual class members. Consequently, the number of damaged shares is commonly estimated from a security's reported daily trading volume. Although the reported trading volume is quite reliable, the number of damaged shares is generally less than reported volume for several reasons.

First, reported volume may overstate the trading volume by the plaintiff class because it includes trades by specialists on the New York Stock Exchange ("NYSE") or market makers on the National Association of Securities Dealers Automated Quotation system ("NASDAQ") who buy from one investor and sell to another. One must adjust the reported volume to remove these doublecounted trades. Recently published research suggests that a suitable correction is obtained by reducing NYSE reported volume by approximately ten percent and reducing NASDAQ volume by approximately fifty-eight percent. ${ }^{4}$

A second adjustment to volume is necessary to eliminate shares that were purchased during the class period and sold before the revelation of the alleged fraud. In many cases, these in-and-out shares have no associated damages because they were purchased and sold at prices with the same artificial inflation. ${ }^{5}$ Historically, it has been common practice among economic experts for both plaintiffs and defendants to adjust volume for non-damaged, in-and-out volume using a statistical trading model. ${ }^{6}$ The trading model is a mathematical model

3. Artificial inflation is the difference between the actual stock price and what the true value of the stock would have been but for the false or misleading information.

4. See Harindra de Silva et al., Securities Act Violations: Estimation of Damages, in Litigation SERVICES HANDBOOK: ROLE OF THE ACCOUNTANT AS EXPERT WITNESS 44-31 (Roman L. Weil et al. eds., 2d ed., 1995); John F. Gould \& Allan W. Kleidon, Market Maker Activity on NASDAQ: Implications for Trading Volume, STAN. J.L. BUS. \& FIN., Fall 1994, at 11, 14, 21.

5. However, in-and-out shares may be damaged if more than one corrective disclosure is involved.

6. See generally de Silva et al., supra note 4, at 44-21 to 44-32; Dean Furbush \& Jeffrey W. Smith, Estimating the Number of Damaged Shares in Securities Fraud Litigation: An Introduction to Stock Trading Models, 49 Bus. LAw. 527, 531 (1994); Jon Koslow, Estimating Aggregate Damages in ClassAction Litigation Under Rule 10b-5 for Purposes of Settlement, 59 FORDHAM L. REV. 811 (1991); Craig 
that estimates, on each day of the class period, the fraction of volume that is inand-out volume and the fraction that is retained volume. ${ }^{7}$

Trading models generally require a calculation of the daily ratio of adjusted volume to float, where float is defined as the number of shares that could have been traded on a given day, and adjusted volume is defined as reported volume adjusted to eliminate intra-day market maker or specialist trades, and to eliminate insider trades. ${ }^{8}$ This "adjusted volume-to-float" ratio is an important factor in virtually all trading models.' In particular, as the number of shares in the float declines, the number of retained shares estimated from a trading model also declines, all else being the same..$^{10}$

It is commonly assumed that each share purchased during the class period has the same chance of being sold on a subsequent day of the class period as any other share in the float. This special case of the GTM is commonly known as the proportional trading (or proportional decay) model because of the proportionality assumption about trading propensities. ${ }^{11}$ The trading propensity assumption is sometimes referred to as the acceleration factor. ${ }^{12}$ The proportionality assumption treats the acceleration factor as equal to one.

If one adopts the proportional trading assumption, then shares purchased on day one of the class period have, on average, a probability of being sold on day two equal to the adjusted volume-to-float ratio on day two. If one assumes that shares purchased during the class period were, on average, more likely to have been sold later in the class period than other shares in the float, then a multiple that is greater than one would be applied to the adjusted volume-to-float ratio. Conversely, if one assumes that shares purchased in the class period were less likely to have been sold later in the class period than other shares in the float, then a multiple that is less than one would be applied to the adjusted volumeto-float ratio. When it is assumed that shares traded during the class period are more likely to be sold later in the class period than other shares in the float, one

McCann et al., Demystifying Stock Trading Models in Securities Class Action Lawsuits (KPMG, Econ. Consulting Serv., N.Y., N.Y.), Aug. 1997, at 1.

7. When the full extent of the fraud is revealed through several partial disclosures, it is usually important to determine the number of shares that were purchased during the class period and held through each partial disclosure. For example, if two distinct stock price drops can be attributed to the fraud, then in-and-out shares purchased before the first price drop, but sold before the second price drop, would normally be damaged in-and-out shares.

8. Float is generally determined by subtracting any shares known not to have traded over a portion of the class period from total shares outstanding. For example, insider trading records and quarterly institutional holdings are used to estimate the number of shares owned by insiders and institutions that were not traded. The float also is adjusted for share offerings or buybacks and for short interest positions. See de Silva et al., supra note 4, at 44-22 to 44-24.

9. Mathematically, the computation of retained shares is a function of the volume-to-float ratio. Specifically, using a GTM $(1 \mathrm{x})$ model, the number of retained shares from purchases on day one of a three-day class period equals the number of shares purchased on day one multiplied by the product of the quantity (one minus the volume-to-float ratio) on day two and the quantity (one minus the volumeto-float ratio) on day three. See id. at 44-25 to 44-32.

10. This mathematical property follows from the algebra of the GTMs.

11. See Furbush \& Smith, supra note 6, at 534.

12. See McCann et al., supra note 6 , at 4 . 
is applying what is called an accelerated trading model. ${ }^{13}$ Although the terms "proportional trading model" and "accelerated trading model" connote separate models, they are both GTMs with different assumptions about trading propensities during the class period. Therefore, this article shall refer to a model as the GTM (1x) when one assumes an acceleration factor of one (proportional assumption), and GTM (1.1x) or GTM (.9x) for acceleration factors of 1.1 and 0.9 , respectively.

III

\section{A COMPARISON OF SINGLE-TRADER AND MULTI-TRADER MODELS}

Recently the proportionality assumption in the GTM (1x) has been criticized. $^{14}$ Theoretical criticisms of the single-trader GTM (1x) center around a mathematical proposition asserted by William Beaver, James Malernee, and Michael Keeley that the number of damaged shares estimated from a twotrader model is substantially less than the number estimated from a proportional trading model. ${ }^{15}$ The two-trader model divides a company's shares into two groups: those held by active traders and those held by passive traders. Daily trading volume for each group is determined by the relative propensities to trade that are assumed for the active-trader and for the passive-trader groups. Given the assumptions about the fraction of shares held by each trader group and the fraction of trading volume attributed to each trader group, estimates of retained shares and in-and-out shares are computed using a GTM (1x) for each group.

The two-trader model has two key assumptions that are not present in the single-trader model: (1) The percentage of total shares outstanding held by active and passive traders are different; and (2) The active and passive traders have different trading propensities (for example, the active trader may be as-

13. See Furbush \& Smith, supra note 6, at 533.

14. The criticism generally has emanated from individuals associated with Lexecon or Cornerstone Research, two firms that provide economic consulting and expert testimony in securities class action cases primarily for defendants. See generally Janet Cooper Alexander, The Value of Bad News in Securities Class Actions, 41 UCLA L. REV. 1421, 1461-62 (1994); William H. Beaver \& James K. Malernee, Estimating Damages in Securities Fraud Cases Slides, in HOW TO PREPARE FOR AND SUCCESSFULly TRY A SECURITIES ClASS ACTION IN THE POST-REFORM ERA 631 (PLI Corp. Law \& Practice Course Handbook Series No. 627, 1990); William H. Beaver et al., Potential Damages Facing Auditors in Securities Fraud Cases, in ACCOUNTANTS' LIABILITY: THE NEED FOR FAIRNESS 113 (John T. Behrendt et al., eds., 1994); Kenneth R. Cone \& James E. Laurence, How Accurate are Estimates of Aggregate Damages in Securities Fraud Cases?, 49 Bus. LAw. 505 (1994); Edward J. Yodowitz \& Steven J. Kolleeny, Changing the Standard of Joint and Several Liability to a Proportional Liability Rule, in SECURITIES Class ACtions: ABuses AND Remedies 31 (National Legal Ctr. for the Public Interest ed., 1994).

15. For example, Alexander offers no independent analysis but merely asserts that "the use of the proportional trading assumption in calculating aggregate class damages accordingly may inflate the total class damages by $100 \%$." Alexander, supra note 14 , at 18 , citing Beaver et al., supra note 14 . Skudder, having cited Alexander and also the empirical findings of Cone and Laurence as his bases, asserts that "because the proportional decay model overstates the retention shares traded during the class period, damages will be overstated." Michael Y. Scudder, The Implications of Market-Based Damages Caps in Securities Class Actions, 92 Nw. U.L. REV. 435, 451 (1997). 
sumed to be two times, five times, ten times, or even twenty times more likely to trade than the passive trader).$^{16}$

Beaver et al. simulate a case in which they assume that the class period is 100 days, the number of shares outstanding is 10 million, daily volume is 100,000 shares, twenty percent of shares are held by active traders, and active traders are twenty times more likely to trade than passive traders. ${ }^{17}$ They report that their two-trader model yields 3,477,350 retained shares. ${ }^{18}$ They compute the number of retained shares using a GTM $(1 \mathrm{x})$ to be $6,339,680 .^{19}$ Because the twotrader model yields only $54.9 \%(3,447,350 / 6,339,680)$ of the retained shares obtained from their GTM (1x), they conclude that the GTM (1x) overstates retained shares and, therefore, overstates aggregate damages. ${ }^{20}$

To illustrate this mathematical proposition, Beaver et al. compared the results of each model to actual depository records that they obtained while working on an unnamed securities case. ${ }^{21}$ The authors state that the class period was 128 days and that the average trading volume was $2.2 \%$ of the shares outstanding. ${ }^{22}$ Their published work claims that their two-trader model matched the actual depository data, which showed that $49.5 \%$ of total shares outstanding were retained and submitted for damage claims. ${ }^{23}$ The results of their GTM $(1 \mathrm{x})$, however, yielded a number of retained shares that was $94.1 \%$ of shares outstanding. ${ }^{24}$

A. Beaver, Malernee, and Keeley's Results from Their GTM (1x) Are Flawed Because They Do Not Compute Float and They Do Not Adjust Reported Volume

In their comparison to the depository records, Beaver et al. mischaracterized how the single-trader GTM is used in current practice. ${ }^{25}$ First, they used total shares outstanding instead of float in their volume-to-float ratio to compute retained shares. ${ }^{26}$ As discussed above, it is standard practice-and critical to the analysis - that the float used to compute retained shares exclude all shares known not to have traded over the class period. ${ }^{27}$ Beaver et al. make no attempt to do so in their GTM (1x). The amount of shares that would typically be ex-

16. The additional assumptions about relative trading propensities and the distribution of trading propensities are viewed by some researchers as a disadvantage. See Edward A. Dyl, Estimating Economic Damages in Class Action Securities Fraud Litigation, 12 J. Forensic ECON. 10, 11 (1999).

17. Beaver et al., supra note 14 , at 125 .

18. See id. at 126.

19. See id.

20. See id. at $126-27$.

21. See id. at 128-30.

22. See id. at 128 .

23. See id.

24. See id.

25. Also, Beaver et al. do not explain whether the depository records they obtained include all trading volume over the class period. See id. at 128-30.

26. See id. at 128.

27. See de Silva et al., supra note 4 , at 44-21 to 44-37. 
cluded from the float is substantial. For example, it is common for float to be less than $50 \%$ of shares outstanding for a class period of only 128 days. $^{28}$

This same confusion over the proper use of the GTM (1x) is evident in the work of Daniel Fischel and David Ross. ${ }^{29}$ They state that an indirect test of the GTM (1x) demonstrates that "the proportional trading decay model would predict that 142.6 million of Intel's 148.7 million shares outstanding were bought during 1990, although the institutional holding data shows that institutions held and did not trade 77.4 million." ${ }^{30}$ Fischel and Ross predetermine the results of their indirect test by omitting an extremely important parameter of the GTM: the number of institutional shares that did not trade..$^{31}$ If they had properly used the institutional data to estimate Intel's float, the number of buy and hold shares predicted could not possibly have exceeded 71.3 million, the number of shares in Intel's float (71.3 million shares in the float is equal to 148.7 million total shares outstanding less 77.4 million shares held and not traded by institutions). ${ }^{32}$ Therefore, Fischel and Ross put forth a straw man calculation of retained shares by failing to adjust the float properly in their model for the institutional trading data. Then they criticize the single-trader GTM because the calculated estimation of retained shares does not comport with the institutional trading data. ${ }^{33}$

Second, Beaver et al. apparently failed to adjust volume for specialist or market-maker trading. ${ }^{34}$ Adjusting the reported volume lowers the number of retained shares. It is common practice to adjust reported volume for specialist (NYSE firms) or market maker (NASDAQ firms) trading. ${ }^{35}$ As previously noted, reported volume should be reduced by approximately twenty percent for NYSE stocks and by approximately fifty-eight percent for NASDAQ stocks. While this adjustment was not discussed in Beaver et al.'s published work, Cornerstone Research summarized the work in its Web page and stated that this adjustment to volume is "an additional problem not discussed here [in their paper]." ${ }^{36}$ Because the authors did not adjust reported volume when they estimated damaged shares, their proportional trading model overstated retained shares by omitting this important parameter.

28. For example, see Plaintiffs Expert Reports, In re Gaming Lottery Sec. Litig., No. 96 Civ. 5567 , 2001 U.S. Dist. LEXIS 1204, at*1 (S.D.N.Y. Feb. 8, 2001).

29. See generally Daniel R. Fischel \& David J. Ross, The Use of Trading Models to Estimate Aggregate Damages in Securities Fraud Litigation: A Proposal for Change, in SECURITIES Class ACTIONS: Abuses AND REMEdies 131 (National Legal Ctr. for the Public Interest ed., 1994).

30. Id. at 139 .

31. See id.

32. This analysis of float does not reflect any effect from insider holdings or short interest positions. See id.

33. See id.

34. See Beaver et al., supra note 14, at 128-30.

35. See de Silva et al., supra note 4, at 44-21 to 44-37; see also Gould \& Kleidon, supra note 4, at 13.

36. William H. Beaver et al., Stock Trading Behavior and Damage Estimation in Securities Cases 8 (1993) (unpublished manuscript, available at the Cornerstone Research website) (last modified Jan. 19, 2000) <http://www.cornerstone.com/fram_sea.html>. 
Chart A of the Appendix shows the results from a simulation using a GTM $(1 \mathrm{x})$ for a class period of 128 days and for average daily volume of $2.2 \%$ of total shares outstanding. With no adjustment to the float or reported volume, the GTM (1x) trading model yields damaged shares that are $94.2 \%$ of shares outstanding, which is similar to the $94.1 \%$ reported by Beaver et al. using actual data. Using the same GTM (1x), but now estimating float to be fifty percent of shares outstanding and adjusting reported volume by the NYSE factor of twenty percent, the number of damaged shares is only $49.2 \%$ of shares outstanding (see Chart A). Therefore, with the correct adjustment to reported volume and plausible assumptions about float, the number of retained shares estimated from a GTM (1x) are approximately equal to the actual number of retained shares as reported by Beaver et al. based on depository records. ${ }^{37}$

B. The Twenty Percent Active and Eighty Percent Passive Trader Assumption Used by Beaver, Malernee, and Keeley Appears to Have Been Chosen to Exaggerate the Differences Between the Proportional Trading Model and the Two-Trader Model

The assumptions that Beaver et al. used to estimate their two-trader model exaggerate the difference between the number of retained shares using the twotrader model and the proportional trading model. Beaver et al. illustrate an example in which active traders hold a constant twenty percent of the stock over a 100 -day class period and active traders are twenty times more likely to trade than passive traders. ${ }^{38}$ They show that the two-trader model yields fifty-five percent of the total retained shares that result from a GTM $(1 \mathrm{x}){ }^{39}$

As Chart B demonstrates, the twenty percent active-trader assumption Beaver et al. chose for their hypothetical example results in the greatest possible difference between the models holding the relative propensity of active and passive traders to trade alike. That is, if one assumes that the active traders held more than twenty percent, or less than twenty percent of the shares outstanding, the number of retained shares from the two-trader model increases, and the difference between retained shares estimated from the two-trader model and retained shares estimated from the GTM (1x) declines.

Moreover, most of the sample data of trading activity do not support the twenty percent active and eighty percent passive distribution asserted by Beaver et al. $^{40}$ To the contrary, the trading data conform more to a normal, bell-shaped distribution. $^{41}$ Kenneth Froot, Andre Perold, and Jeremy Stein present a decomposition of share turnover for nine groups of traders: Active Pension Funds, Passive Pension Funds, Foundations/Endowments, Self-directed Households,

37. Since Beaver et al. reveal neither the company nor the class period for which they are calculating damaged shares, it is not possible to make an accurate assessment of the float.

38. See Beaver et al., supra note 14 , at 126.

39. See id.

40. See Kenneth A. Froot et Al., Shareholder Trading Practices and Corporate INVESTMENT HORIZONS (National Bureau of Econ. Research Working Paper No. 3638, 1991).

41. See id. at 57 tbl. 1. 
Bank Trust Departments for Households, Insurance Companies, Mutual Funds, Foreign Investors, and Others. ${ }^{42}$ Froot et al. report the percentage held by each group and the average share turnover for each group. ${ }^{43}$

Using turnover statistics from Froot et al., relative trading propensities were computed by dividing each group's reported turnover statistic by the turnover statistic for the group with the lowest turnover (Passive Pension Funds). The trading propensities ranged from 1.0 to 7.4. The data show that five percent of equity holdings are Passive Pension Funds that have the lowest turnover and thus a trading propensity of one. Approximately fifty-six percent of equity holdings have a trading propensity between 1.5 and 1.9 , approximately thirtytwo percent of equity holdings have trading propensities between 2.9 and 3.8, and seven percent of equity holdings have trading propensities between 6.5 and 7.4. Chart A shows the results of this calculation.

These statistics were used to estimate a four-trader model before comparing the results from this four-trader model with the GTM (1x) using the same assumptions about daily volume and float used by Beaver et al. The number of retained shares estimated from the four-trader model using the statistics from Froot et al. are approximately ninety-two percent of the results from the GTM $(1 \mathrm{x})$.

Thus, a more sophisticated multi-trader model that makes use of actual data about trading propensities results in retained shares estimates that are quite similar to that of the GTM (1x). This result should not be surprising. The GTM (1x), when used correctly, is essentially a two-trader model because shares are eliminated from the float and therefore eliminated from damages. Shares that are eliminated from the float have a trading propensity that is equal to zero, because they are known not to have traded during the class period. Thus, the model has one (often large) group of traders with a known trading propensity of zero during the class period. Shares that remain in the float, by design, have much more homogeneous trading propensities because the shares with the lowest trading propensities have been removed from total shares outstanding.

The sensitivity of the four-trader model results was tested by maintaining the general bell-shaped distribution for the number of traders in each trader group while increasing the range of relative trading propensities. That is, the study assumed that the lowest and highest trading-propensity groups are each approximately five to seven percent of shares outstanding but increased the range of trading propensities. Even assuming that the highest trading propensity is forty times greater than the lowest trading propensity, the results were still eighty-nine percent of the GTM (1x) (see Chart B). Thus, if the multitrader model is applied with a distribution of traders that conforms to the observed empirical data, it does not result in the exaggerated differences of nearly fifty percent when compared with the proportional trading model as asserted by

42. See id.

43. See id. 
the critics. The unrealistic trading propensities assumed by Beaver et al. in their two-trader model significantly understate the number of retained shares when compared with a multi-trader model using a distribution of trading propensities that is more consistent with observed trading propensities.

C. The Magnitude of the Difference Between the Two-trader Model and the GTM (1x) Is Sensitive to the Length of the Class Period

Beaver et al. use a hypothetical class period of 100 days when they compare the results from a proportional trading model with a two-trader model. ${ }^{44}$ Chart $\mathrm{C}$ shows the ratio of the number of retained shares from the two-trader model (with twenty percent active shares and eighty percent passive shares) to the number of retained shares from the GTM (1x) for various assumptions about relative trading propensities and the length of the class period. Chart $\mathrm{C}$ illustrates that as the class period becomes shorter than 100 days or greater than 150 days, this ratio increases using any assumption about trading propensities.

\section{IV}

\section{EMPIRICAL EVIDENCE}

Kenneth Cone and James Laurence's work is the most frequently cited empirical evidence on the accuracy of trading models. They cite two cases in which the damage estimates from the plaintiffs' experts, who used a proportional trading model, exceeded the aggregate claims filed. ${ }^{45}$ Cone and Laurence criticize the proportional trading assumption (referring to it as the "uniform" assumption) on several grounds and state that "the ultimate test of any model lies in how well it predicts the bottom line." ference between the predicted aggregate damages and the actual aggregate damages awarded through the claims process. ${ }^{47}$ The two cases they cite involve Midwestern and Storage Technology, NASDAQ and NYSE stocks, respectively.

\section{A. Testing Trading Models with Anecdotal Claims Data Can Be Grossly Misleading}

1. Storage Technology. For the Storage Technology case, Cone and Laurence report that the proportional trading model overestimates the number of buy-and-hold shares that entered the class compared with the buy-and-hold claims submitted. ${ }^{48}$ They report that for Storage Technology, only 9.3 million

44. See Beaver et al., supra note 14, at 125 .

45. The two cases cited are Biben v. Card, 789 F. Supp. 1001 (W.D. Mo. 1992) and Levit v. Aweida, 630 F. Supp. 1072 (D. Colo. 1986). See Cone \& Laurence, supra note 14, at 507.

46. Id. at 522,530 .

47. See id. at 530 .

48. See id. at 537 . 
buy-and-hold shares were submitted for a claim, which was about one-third of the estimated buy-and-hold shares from their proportional trading model. ${ }^{49}$

A comprehensive analysis of share ownership in the Storage Technology case, however, demonstrates that use of claims data as a benchmark for the number of Storage Technology shares that were bought and held is misleading and inappropriate. In reaching this conclusion, institutional holdings of Storage Technology over the class period as reported by Thomson Financial Securities Data ("Thomson") were reviewed. Thomson records the shares of a stock held by each institution at the end of each quarter from the 13-F Securities and Exchange Commission ("SEC") filings that institutions are required to file. According to Thomson, there were 135 institutions that held 15.6 million shares (approximately fifty percent of shares outstanding) of Storage Technology at the end of the quarter before the beginning of Storage Technology's class period. The data show that approximately 15.4 million of the 15.6 million shares owned by institutions were sold during the class period. ${ }^{50}$ Thus, the 9.3 million shares submitted for claims reflect only sixty percent of the buy-and-hold shares originally held by institutions and none of the buy-and-hold shares originally held by individual investors (who owned approximately fifty percent of the total shares outstanding). The 9.3 million buy-and-hold shares submitted for claims are a misleading and inappropriate benchmark for assessing the efficacy of any trading model.

Just how poor is the use of claims data to assess the trading model for Storage Technology? Although we do not have data on individual shareholders as we do for institutions, certain facts about this case may provide some insight. The class period is over two years long, Storage Technology lost seventy-five percent of its market value of equity over the same time period in which the market increased by sixty-five percent, and institutions turned over nearly their entire holdings of Storage Technology stock during the class period. ${ }^{51}$ Reported volume over the class period was over 125 million shares, which, with 33 million shares outstanding, reflects a share turnover of about $380 \%{ }^{52}$ It would be remarkable to find that that many individuals who held Storage Technology stock before the class period did not sell during the class period. Thus, the number of buy-and-hold shares from claims submissions vastly underestimates the actual number of shares of Storage Technology that were bought and held.

Contrary to the conclusion of Cone and Laurence, the proportional trading model may well provide a very good estimate of buy-and-hold shares in this case. It is clear, however, that Storage Technology's claims data are of little use

49. See id.

50. For each institution, the lowest balance of shares it held during the class period was determined before subtracting that balance from the number of shares it held before the beginning of the class period.

51. See S\&P 500 Index, Standard and Poors (visited Mar. 8, 2001) <http://www.spglobal.comindex main500_data.html>; Center for Research in Securities Prices (visited Mar. 7, 2001) <http://www.gsb. uchicago.edu/research/crsp/index/html $>$.

52. See Center for Research in Securities Prices, supra note 51. 
in assessing whether the number of buy-and-hold shares predicted by the GTM $(1 \mathrm{x})$ is accurate (see Chart C). This is because the Storage Technology case is an old case dating back to 1982, and the case was decided over six years after the end of the class period at issue..$^{53}$ According to deposition testimony, the claims administration for this case was poorly conducted by today's standards. ${ }^{54}$ Evidently, the proof of claims form was difficult to understand as the form said nothing about damages and was required to be returned by registered mail. ${ }^{55}$

2. Midwestern. For Midwestern, Cone and Laurence report in Table 6 of their report that the buy-and-hold shares submitted for claims equaled eightyseven of the shares predicted from a GTM (1x) when a proper adjustment to NASDAQ reported volume was used. ${ }^{56}$ Considering the potential for claims data to vastly underestimate actual buy-and-hold shares, as evidenced by the Storage Technology case, this difference of 230,000 shares $(13 \%$ of the 1.78 million share prediction) would appear to support the GTM (1x) result, rather than to provide evidence against its use (See Table D). It is not contended here that the Midwestern claims data supports the use of the proportional trading model, but rather that the claims data fail to support the critics' contentions that the proportional trading model dramatically overstates retained shares.

B. Testing Trading Models with Anecdotal Claims Data Can Be Inappropriate

Cone and Laurence simultaneously test the efficacy of the proportional assumption and the reasonableness of plaintiffs' damages theory. In most of their analysis, Cone and Laurence focus on aggregate dollar damages rather than on the number of damaged shares. ${ }^{57}$ Because they compare the aggregate dollar damages estimated with a proportional trading model with the aggregate damage claims, their analyses involve a simultaneous testing of the results of the proportional trading model (damaged shares) and the plaintiff's damage theory (artificial inflation per share). Unless the per share damages used in claims administration are exactly the same as the per share damages used by the damages expert, estimated aggregate dollar damages will always deviate from the aggregate dollar damages that result from claims. This deviation will occur even if the number of damaged shares estimated by the expert equals the number of damaged shares derived from claims.

Therefore, the comparison of predicted and actual aggregate dollar damages is of limited usefulness when testing the accuracy of a particular trading model because the comparison confounds the effects of the damage theory (value line) and the effects of the trading model itself. Although there is certainly a strong

53. See Deposition Testimony of John Torkelsen, Ziemack v. Centel, No. 92-C-3551, 1997 U.S. Dist LEXIS 2198 (N.D. Ill. Feb. 26, 1997).

54. See id.

55. See id.

56. Cone and Laurence reduce the reported volume by $67 \%$, which they indicate is within the plausible range for the NASDAQ reporting bias. See Cone \& Laurence, supra note 14, at 515.

57. See generally Cone \& Laurence, supra note 14. 
connection between aggregate damages and the number of damaged shares, conclusions about the accuracy of trading models should not be dependent upon a particular damage theory.

Moreover, there is an important economic distinction between the number of damaged shares and the number of shares submitted for claims in class action securities litigation. In any securities litigation, it is unlikely that all shareholders who were damaged would file claims. Each shareholder faces an economic decision about whether the time and effort required to retrieve trading records and complete the proof of claims forms is worth the expected damage award. But this individual decision about whether to file a claim does not alter the economic fact that a given share was damaged.

Understanding the relation between trading models and claims data can provide important insights about both the trading model and the claims process. But, given the fundamental economic distinction between damaged shares and claims filed, Cone and Laurence are making a legal conclusion when they assert that the test of a trading model is its ability to predict claims. This conclusion is erroneous, and the logic behind it is flawed in a way that may result in bad public policy, as explained below.

It is generally accepted that the number of claims filed in a given case is a function of the amount of the damage award. The greater the damage award, the more likely shareholders are to spend their time and resources retrieving trading records and completing the proof of claims forms. The damage award is, in turn, a function of the predicted aggregate damages that are based in part on the results of a trading model. Therefore, it follows logically that the number of expected claims filed is a function of the predicted damages. Thus, trying to estimate the number of claims filed in the damage calculation is circular. That is, the lower the damage estimate, the lower the number of expected claims will be, but the lower the number of expected claims, the lower the damage estimate will be, and so on. This circular logic is in itself a compelling reason to keep the damages estimates separate from any estimates of claims filed.

\section{More Recent Evidence from Claims Data}

The two cases cited by Cone and Laurence provide only anecdotal evidence regarding the ability of trading models to predict claims data. Conclusions from a sample of two observations will not have a high degree of statistical significance, particularly when the results of the analyses differ dramatically between the two cases.

In addition, the two cases examined by Cone and Laurence are now quite old. There are other more recent cases in which the claims data do not support the critics' contentions that the proportional trading model overestimates the number of damaged shares. For example, in the In re Health Management, Inc. Securities Litigation case, plaintiffs' expert estimated that 5.631 million shares 
were damaged based on a GTM $(1 \mathrm{x}) .^{58}$ The claims data showed that 5.014 million shares, or eighty-nine percent of the estimated number of damages shares, were submitted for claim. ${ }^{59}$ Furthermore, had the plaintiffs' expert reduced reported NASDAQ volume by sixty-seven percent, as advocated by Cone and Laurence, instead of the fifty percent reduction actually used, the damaged shares from claims submissions as a percent of the GTM (1x) estimated shares would be greater than ninety percent. Therefore, it is more reasonable to conclude that the $\operatorname{GTM}(1 \mathrm{x})$ is supported by the claims data in this case.

V

\section{SUMMARY}

Single-trader models (including the proportional and accelerated trading models) and multi-trader models are all GTMs with different assumptions and/or parameters. This article compared the results of these models and critically evaluated the conclusions reached in previously published research.

Beaver, Malernee, and Keeley's comparison between their two-trader model and the proportional trading model is flawed because they do not compute float and they do not adjust reported volume. ${ }^{60}$ Furthermore, the twenty percent active to eighty percent passive trader assumption used by Beaver et al. appears to have been chosen to exaggerate the differences between the proportional trading model and the two-trader model. The unrealistic trading propensities assumed in their two-trader model significantly understates the number of retained shares when compared with a multi-trader GTM using a distribution of trading propensities that is more consistent with actual observed trading propensities.

The most often cited empirical evidence on the accuracy of the trading models is of highly questionable use. First, testing trading models with claims data can be misleading and inappropriate. Second, the individual decision of whether to file a claim does not alter the economic fact that a given share was damaged. Moreover, given the fundamental economic distinction between damaged shares and claims filed, the logic of using claims data as a benchmark is flawed in a way that may result in bad public policy.

The differences between actual damaged shares and shares reported as damaged from claims data are significant and appear to vary greatly from case to case. In the Storage Technology case, the 9.3 million shares submitted for claims reflect only sixty percent of the buy-and-hold shares originally held by institutions that owned approximately fifty percent of the total shares outstanding before the class period and subsequently sold during the class period.

58. Order Approving Distribution of Settlement Fund, In re Health Management, Inc. Sec. Litig., 180 F.R.D. 40 (E.D.N.Y. 1999) (No. CV 96-889 (ADS)(ARL)).

59. See Rule 26 Report of J.B. Torkelsen, In re Health Management, Inc. Sec. Litig., 180 F.R.D. 40 (E.D.N.Y. 1999) (No. CV 96-889 (ADS)(ARL)); Deposition Testimony of J.B. Torkelsen, Oct. 20, 1999, at 1352-53, Health Management (No. CV 96-889).

60. See Beaver et al., supra note 14 , at 128-30. 
Thus, the 9.3 million buy-and-hold shares submitted for claims are a misleading and inappropriate benchmark, because that figure is well short of the actual damaged shares for institutional holders alone.

Conclusions from a sample of two observations will not have a high degree of statistical significance, particularly when the results of the analyses differ dramatically between the two cases as they do here. Furthermore, the two cases examined by Cone and Laurence are now dated, and there are other more recent cases in which the claims data do not support the critics' contention that the proportional trading model overestimates the number of damaged shares.

The results of the single-trader GTM (1x) are consistent with the results of multi-trader GTMs when appropriate assumptions and parameters are used. The estimated damaged shares from a properly specified four-trader model in which the trading propensities are generated from the observed empirical distribution yields about ninety-two percent of the estimated damaged shares from a GTM (1x). Thus, there is no evidence that would reject the GTM (1x) as a scientific method to estimate the number of damaged shares in securities litigation. 


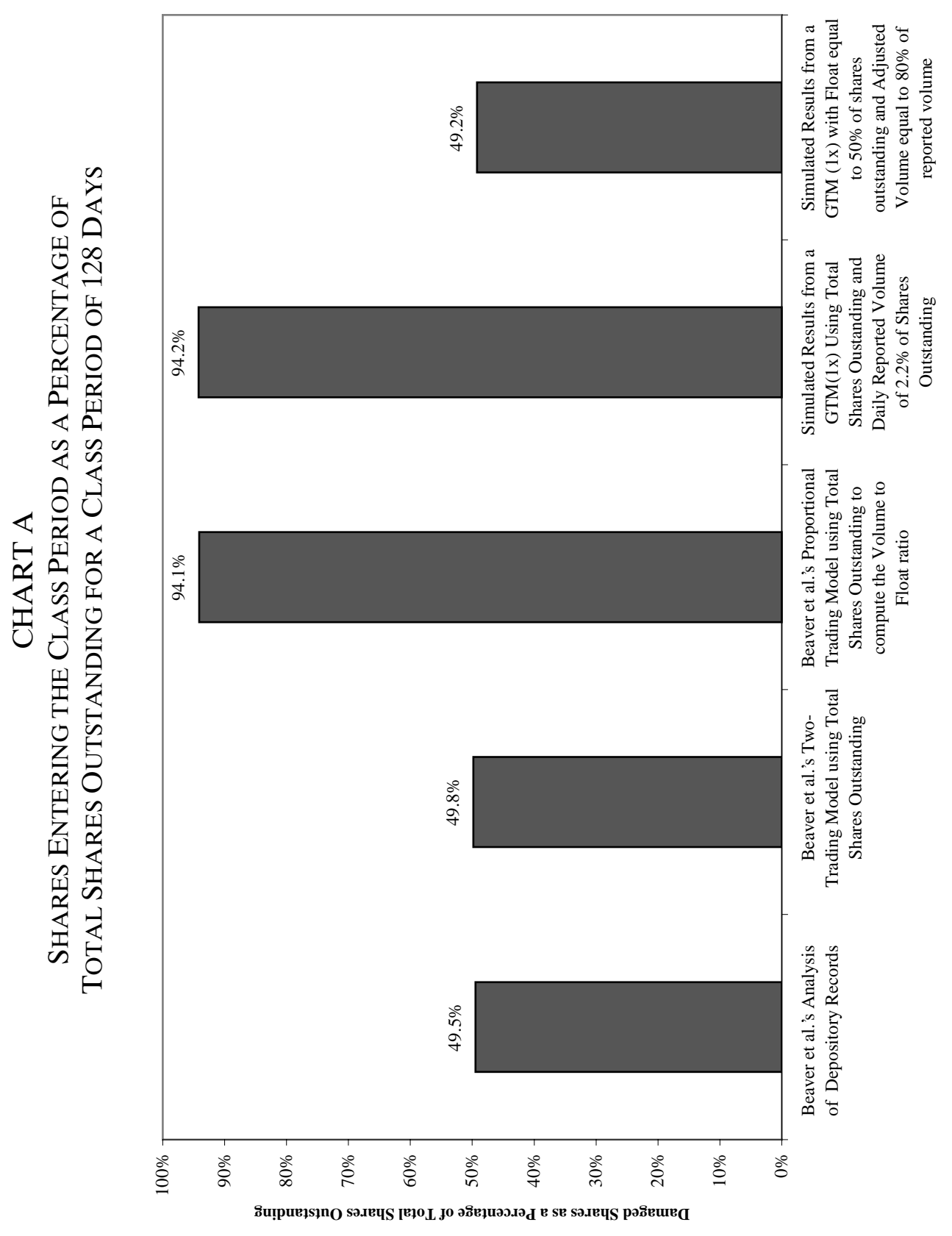




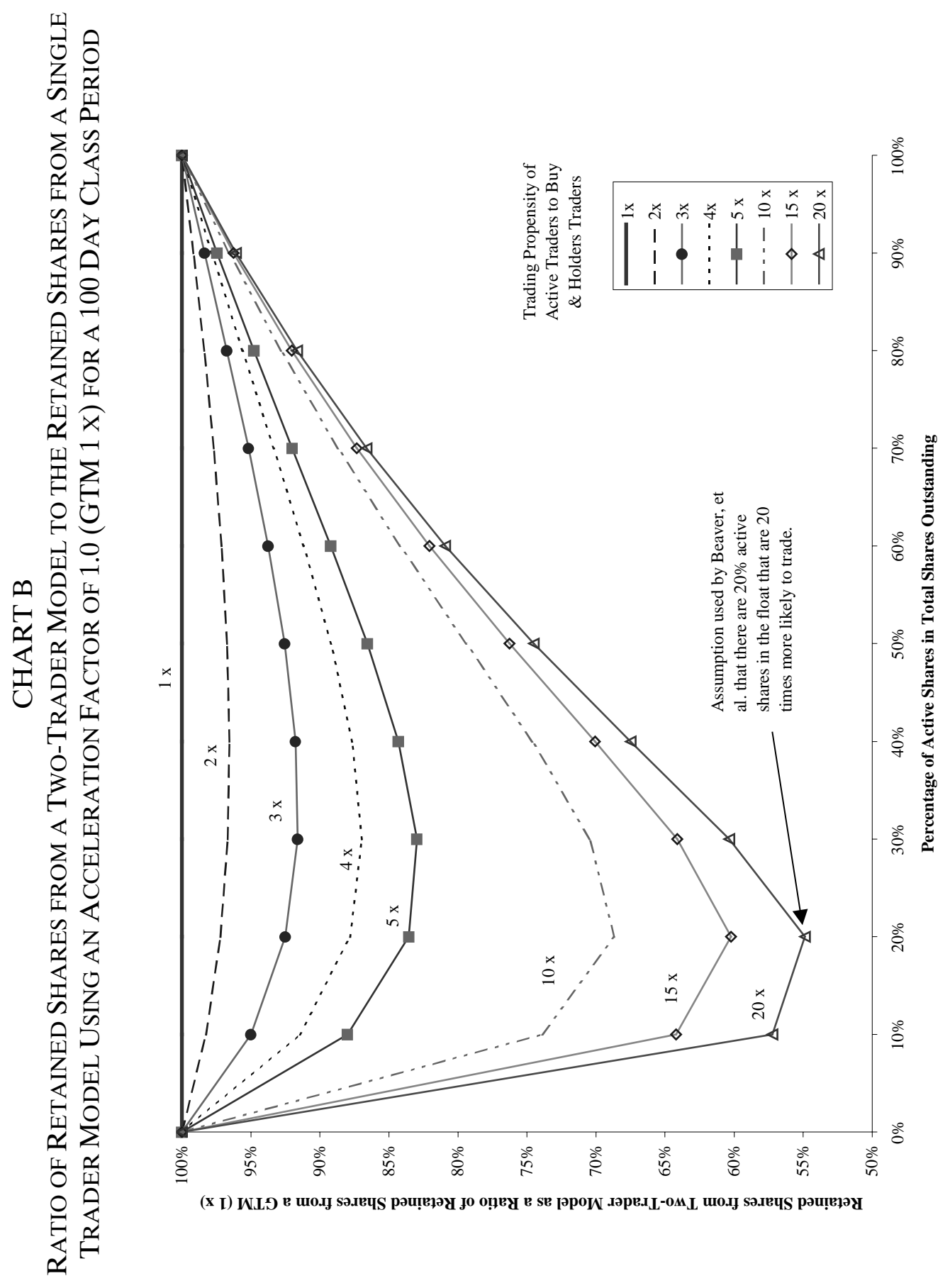




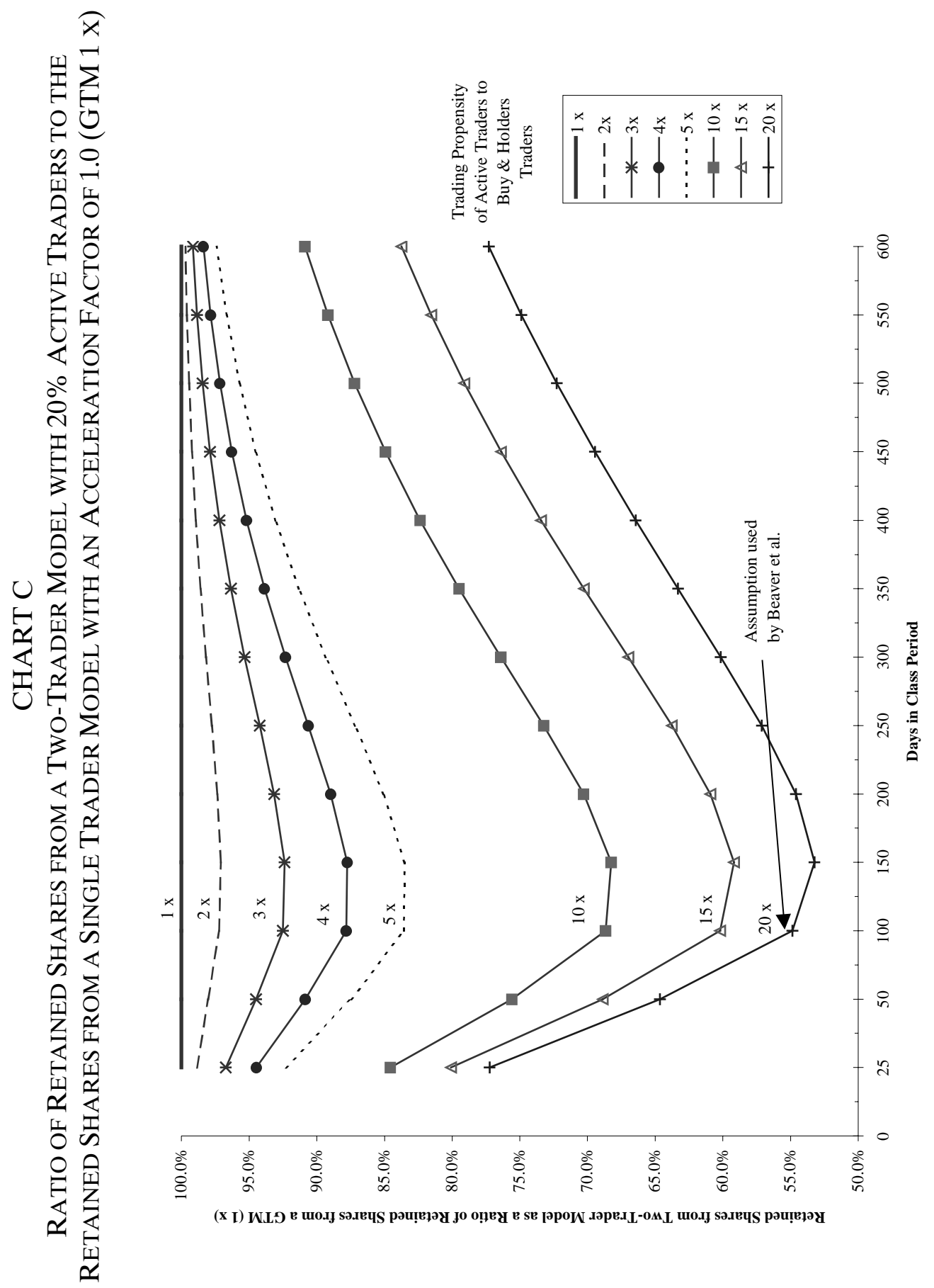




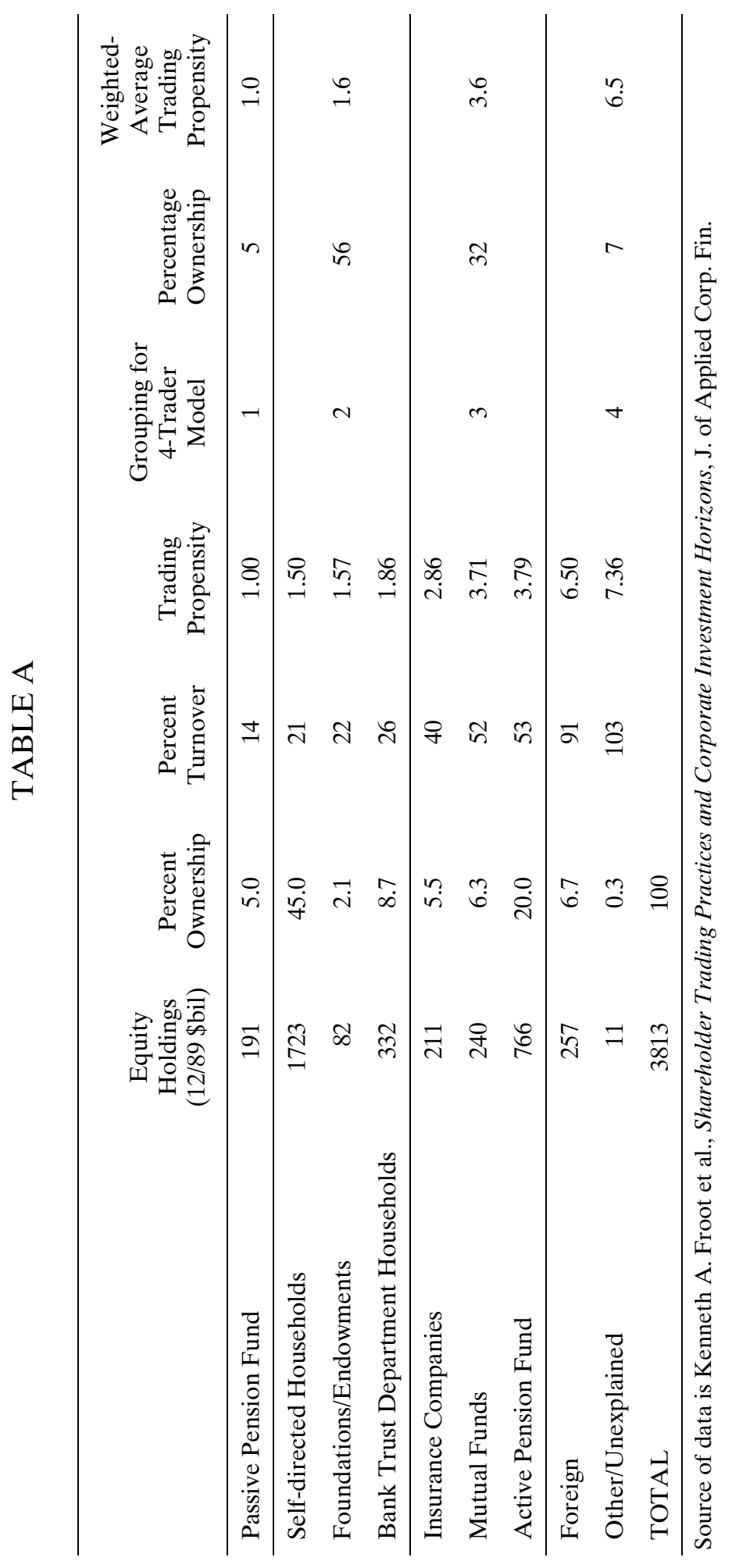


TABLE B

Total Float $=$ shares Outstanding

$10,000,000$

Daily Volume

100,000

Days in Class period

100

\begin{tabular}{lc} 
GTM $(1 \mathrm{x})$ & Total \\
\hline Acceleration Factor & 1.0 \\
Retained Shares & $6,339,677$ \\
\hline
\end{tabular}

Four Trader Model Based on Data from Froot et al.

\begin{tabular}{lccccc} 
& Total & $\mathbf{1}$ & $\mathbf{2}$ & $\mathbf{3}$ & $\mathbf{4}$ \\
\hline Fraction of Float & $100 \%$ & $5 \%$ & $56 \%$ & $32 \%$ & $7 \%$ \\
Propensity to Trade & NA & 1.0 & 1.6 & 3.6 & 6.5 \\
Daily Volume & 100,000 & 1,966 & 35,114 & 45,025 & 17,895 \\
& & & & & \\
Retained Shares & $5,838,155$ & 162,848 & $2,611,896$ & $2,415,942$ & 647,469 \\
Percent of GTM (1x) & $92.1 \%$ & & & & \\
\hline
\end{tabular}

Four Trader Based on Sensitivity Analysis on Trading Propensities

\begin{tabular}{lccccc} 
& Total & 1 & 2 & 3 & 4 \\
\hline Fraction of Float & $100 \%$ & $5 \%$ & $56 \%$ & $32 \%$ & $7 \%$ \\
Propensity to Trade & NA & 1.0 & 10.0 & 30.0 & 40.0 \\
Daily Volume & 100,000 & 278 & 31,052 & 53,088 & 15,582 \\
& & & & & \\
Retained Shares & $5,629,189$ & 27,071 & $2,386,391$ & $2,589,426$ & 626,300 \\
Percent of GTM $(1 \mathrm{x})$ & $88.8 \%$ & & & & \\
\hline
\end{tabular}




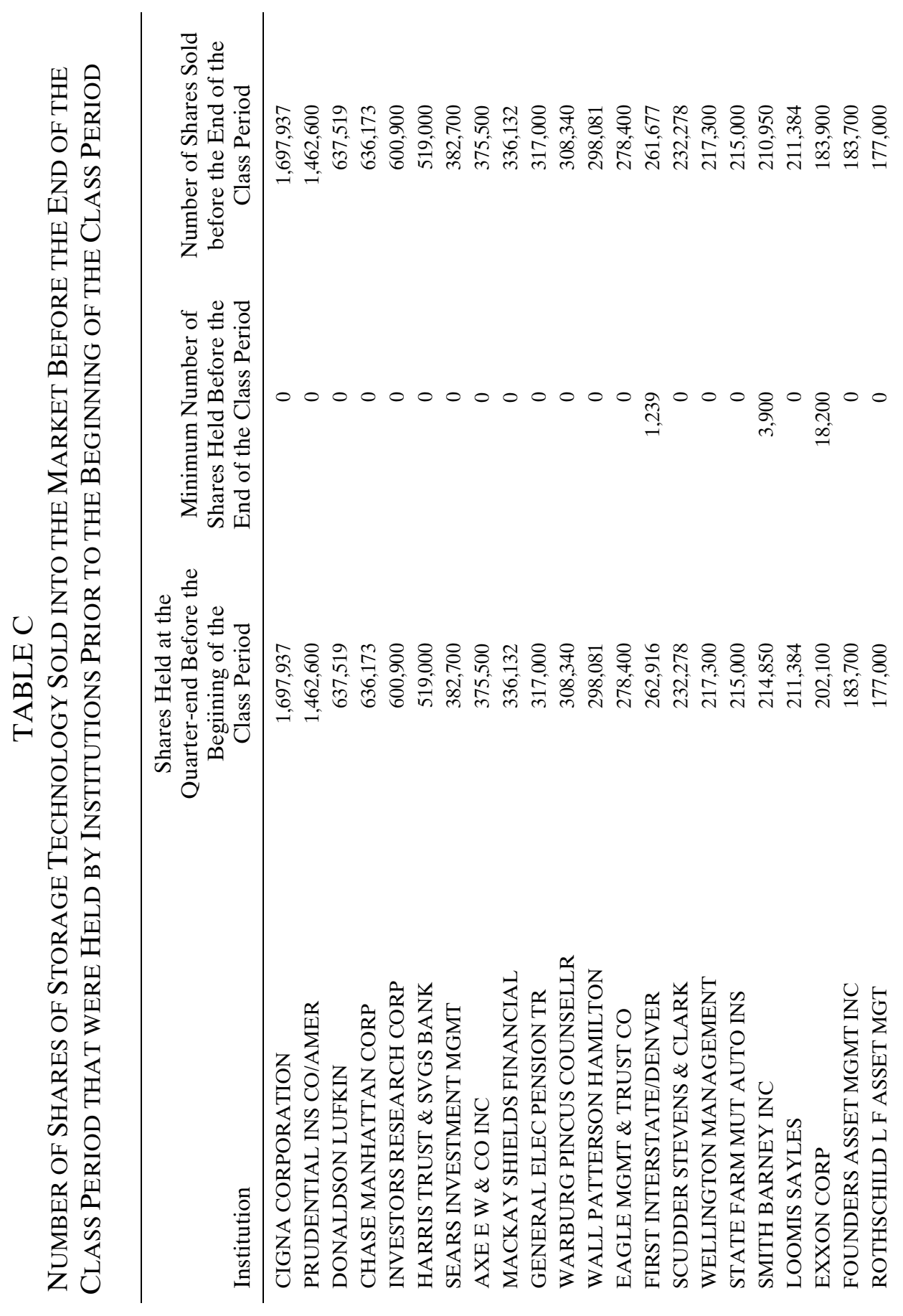




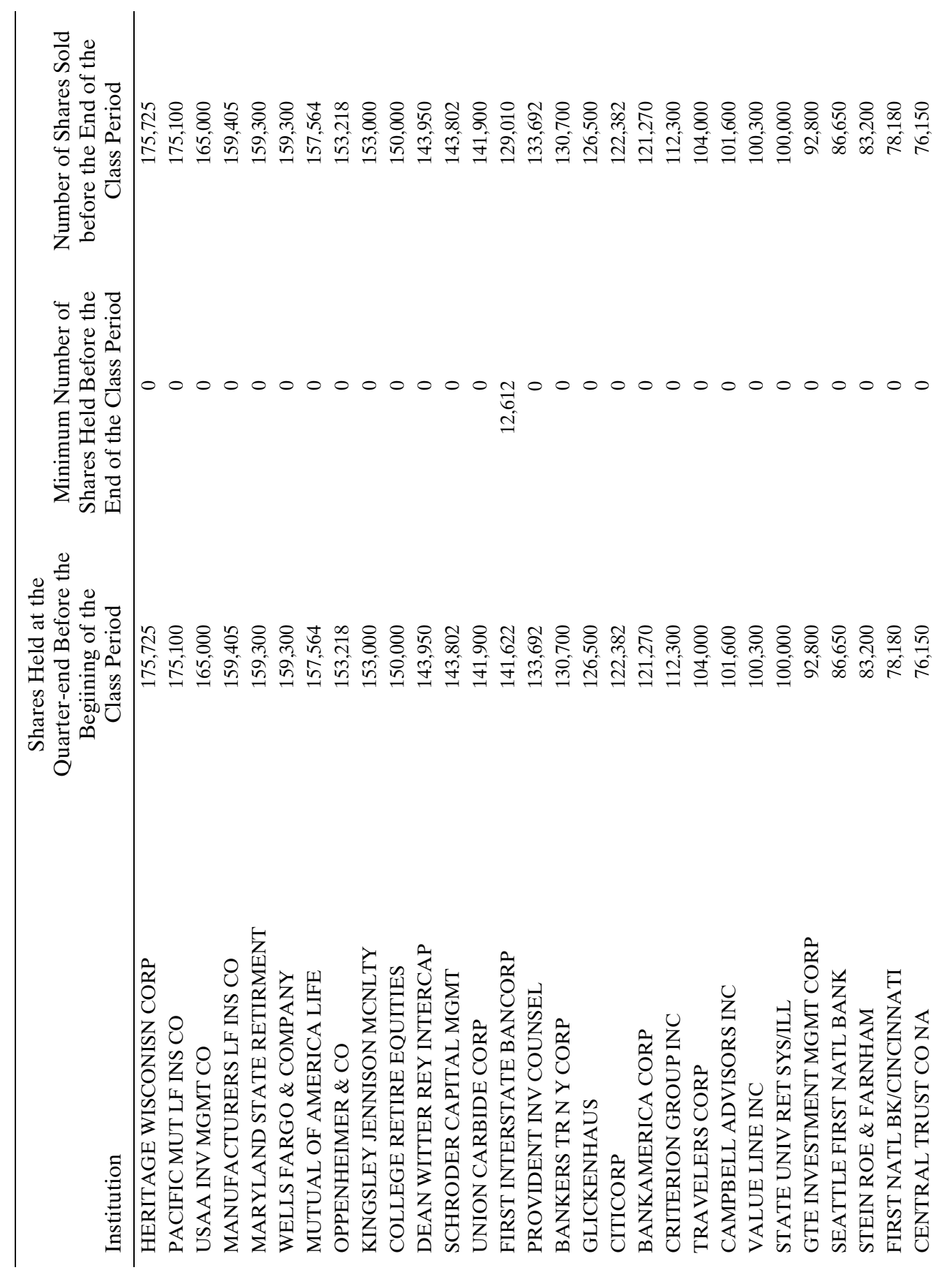




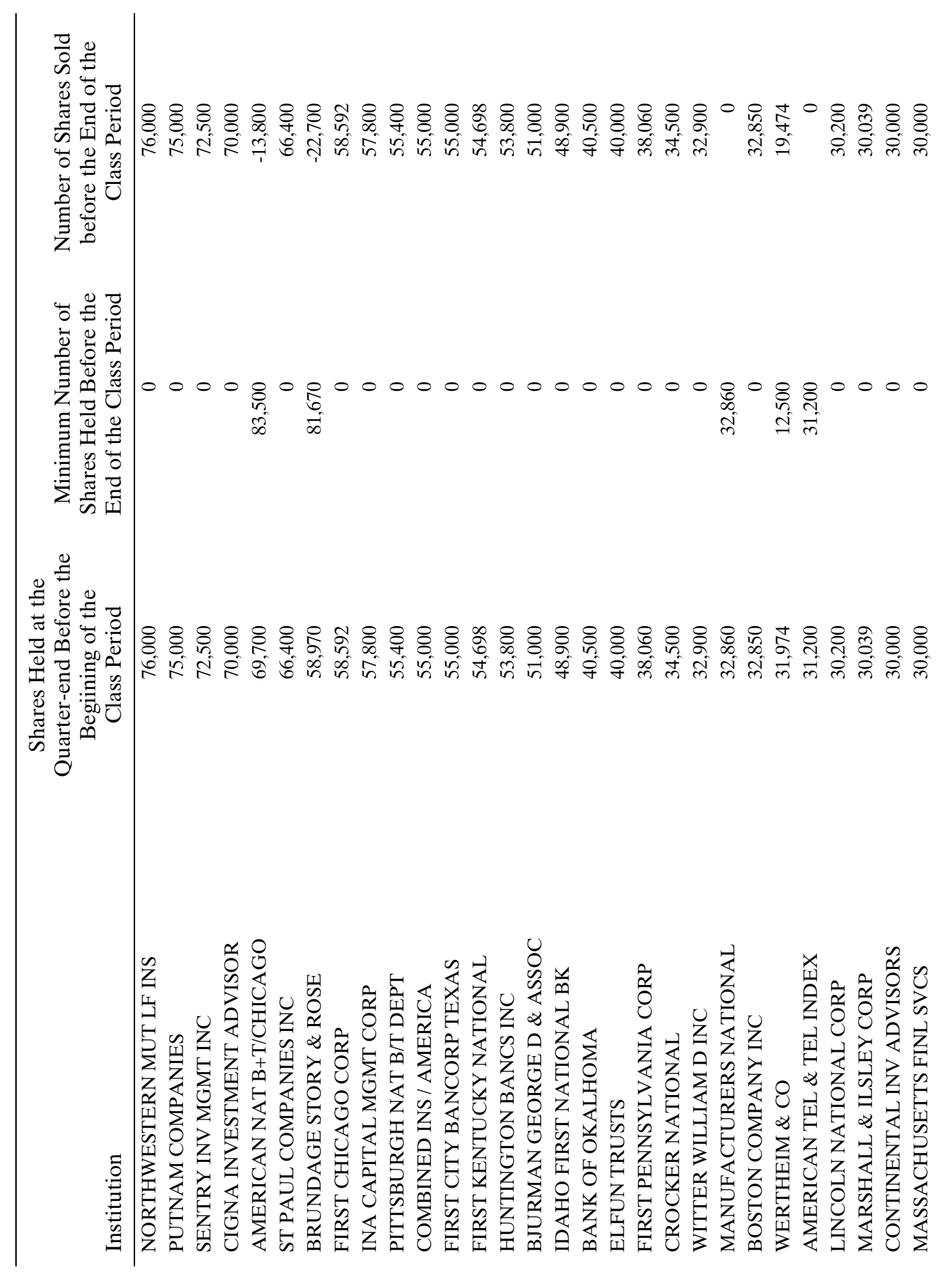




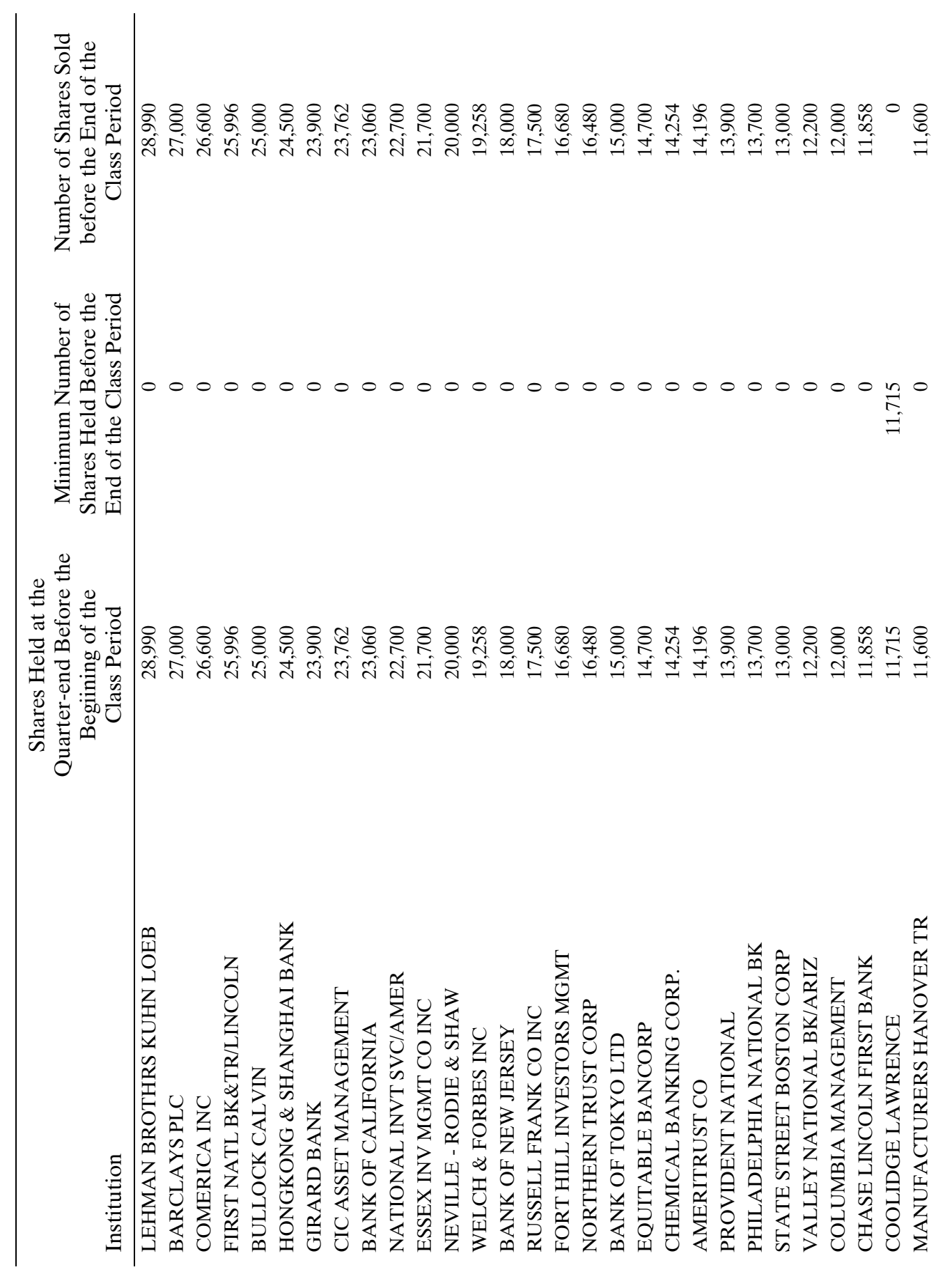




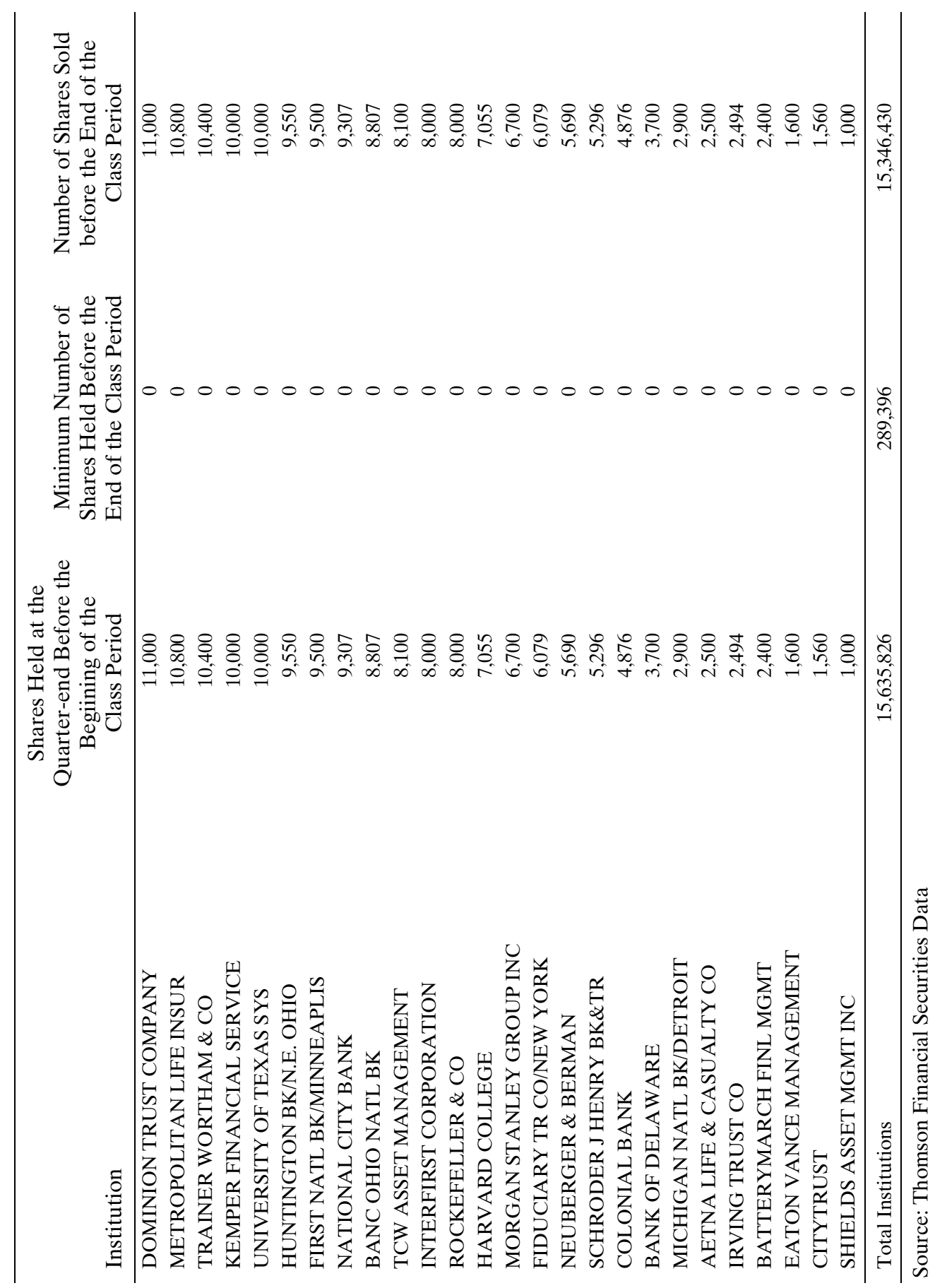




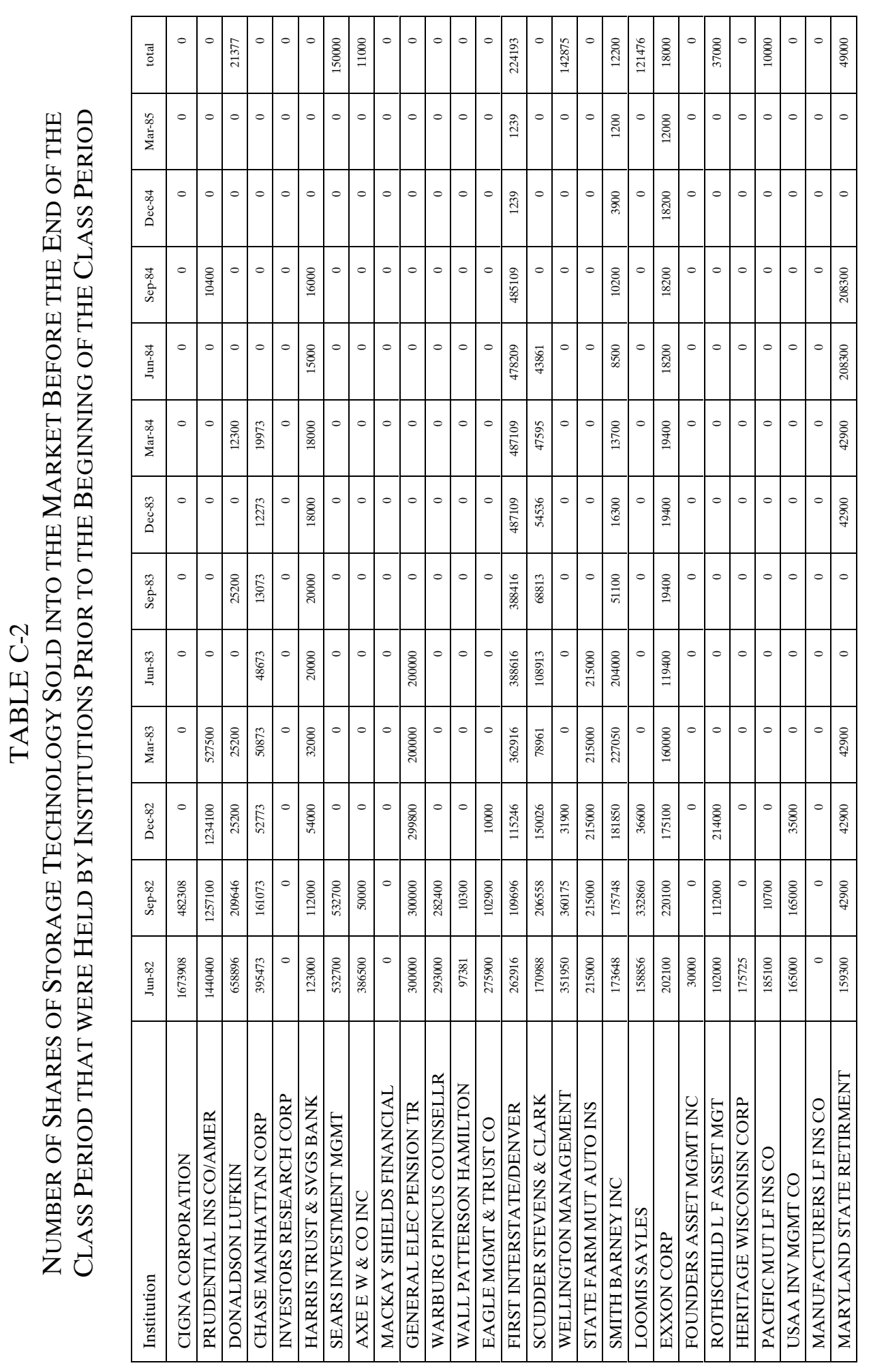




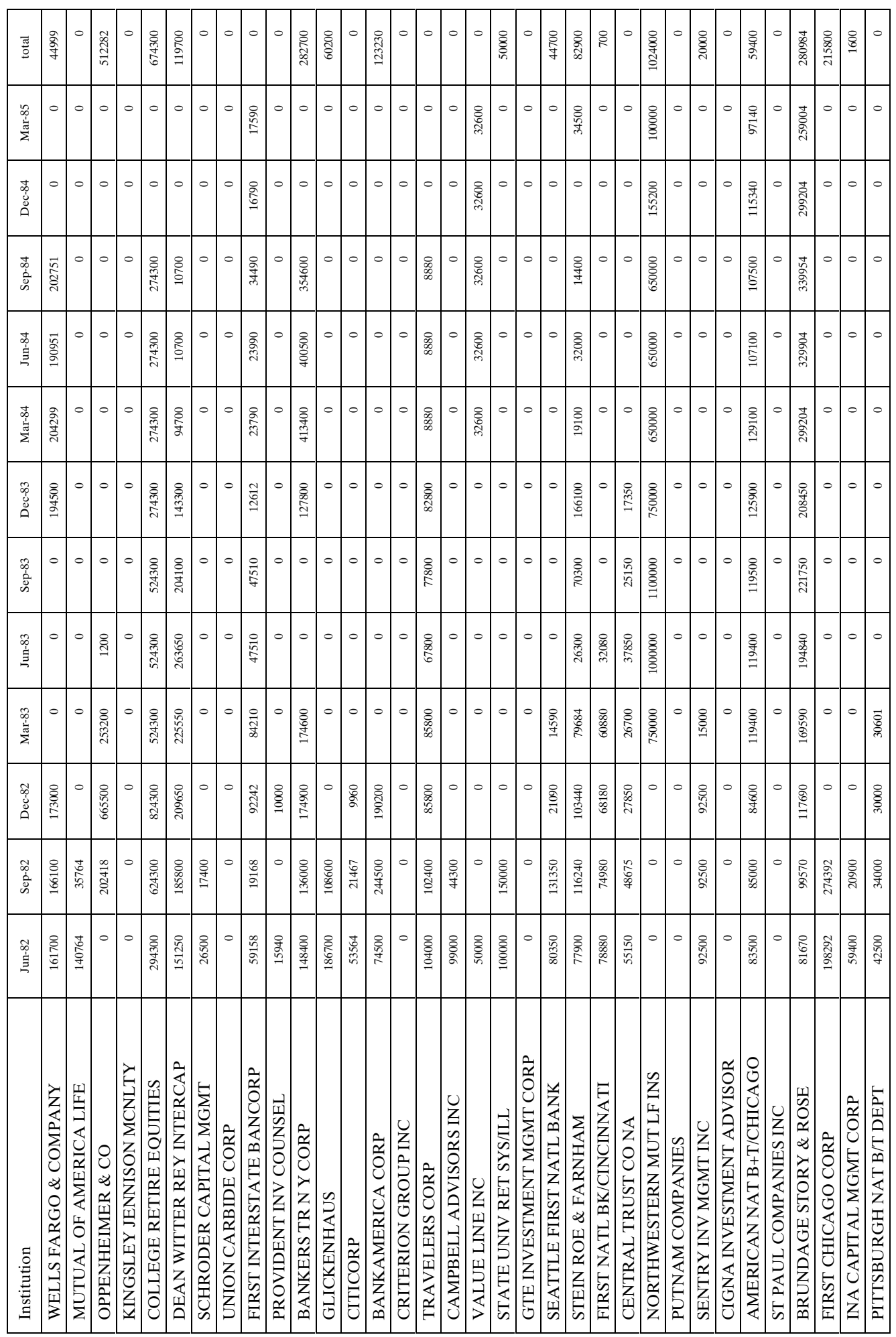




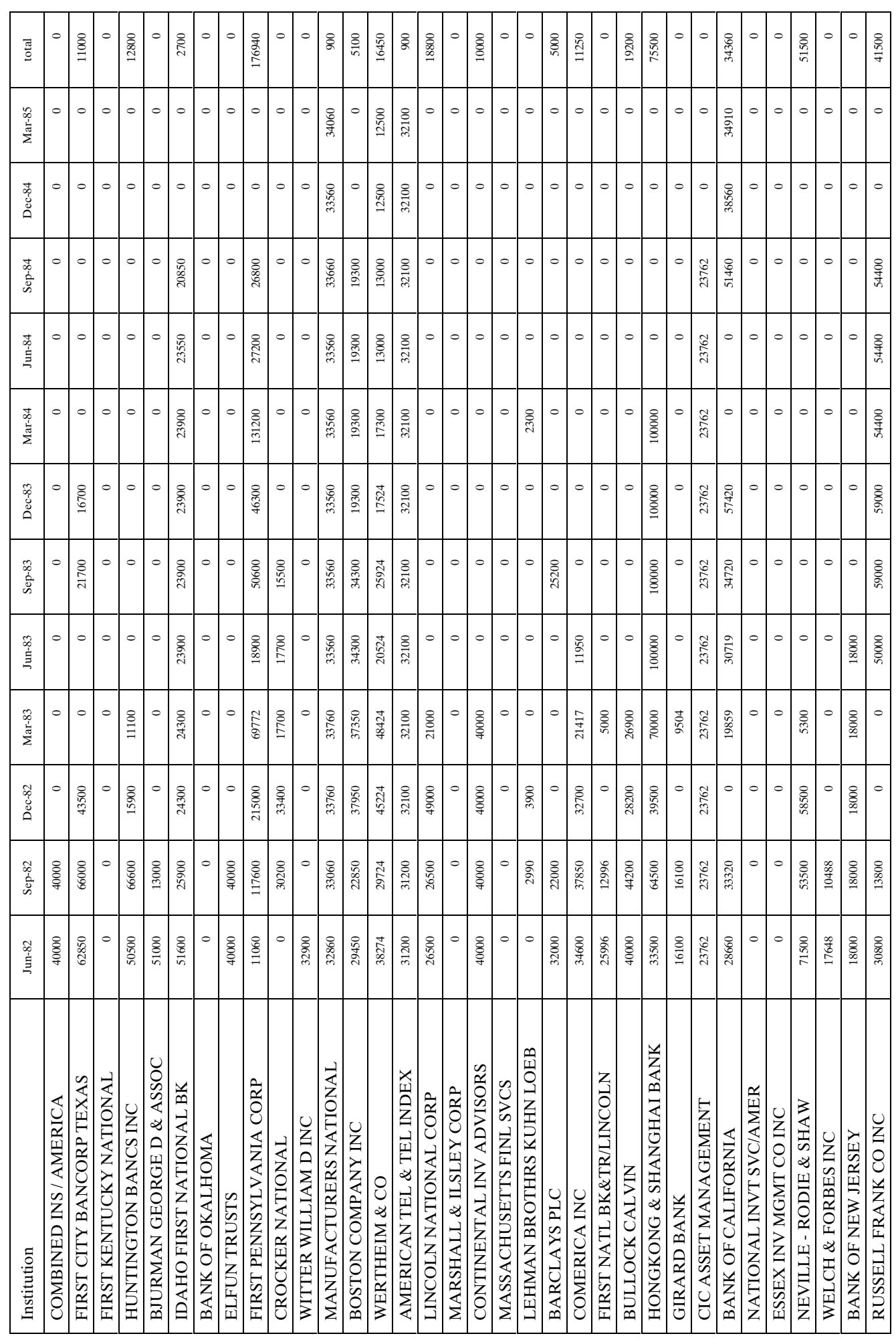




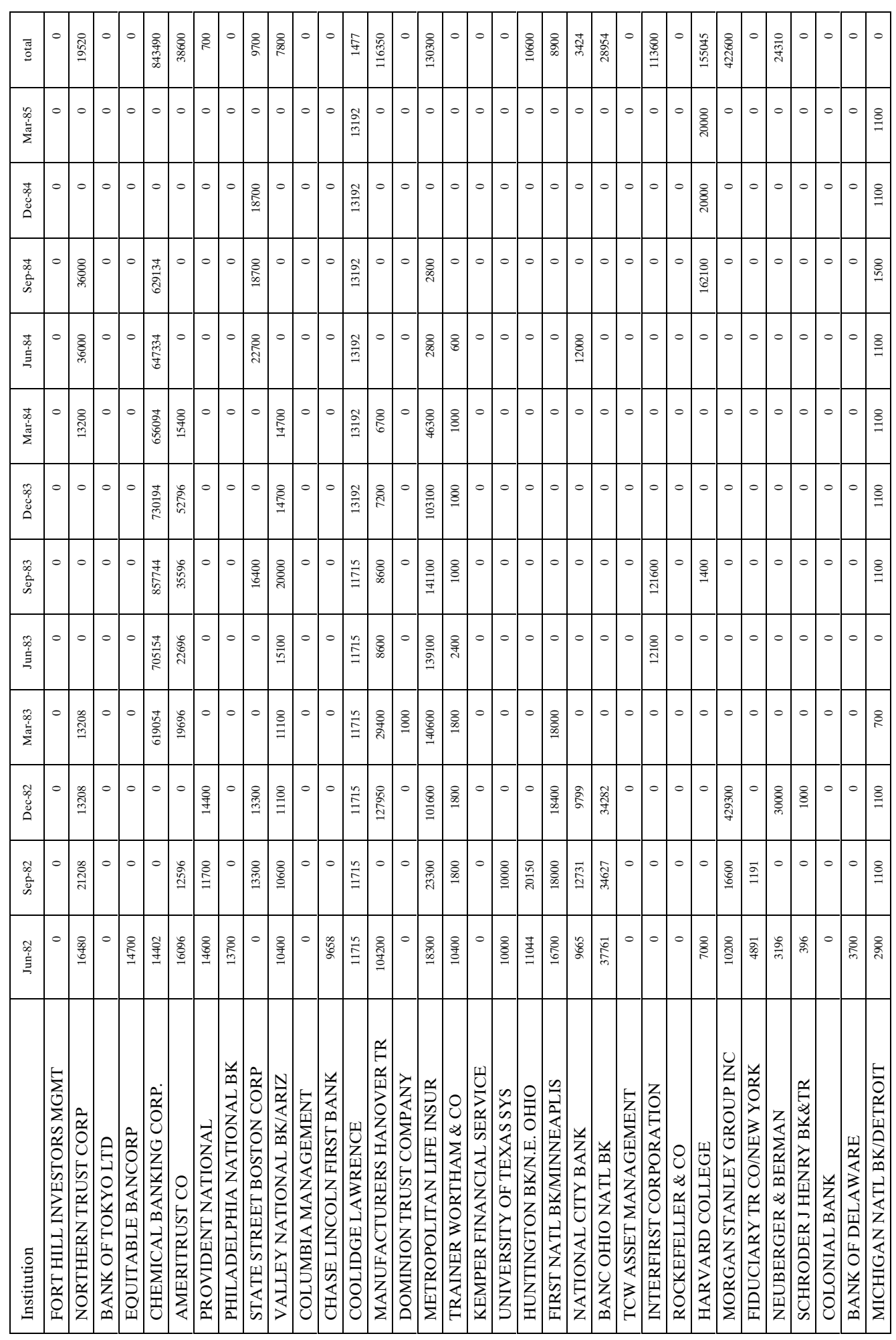




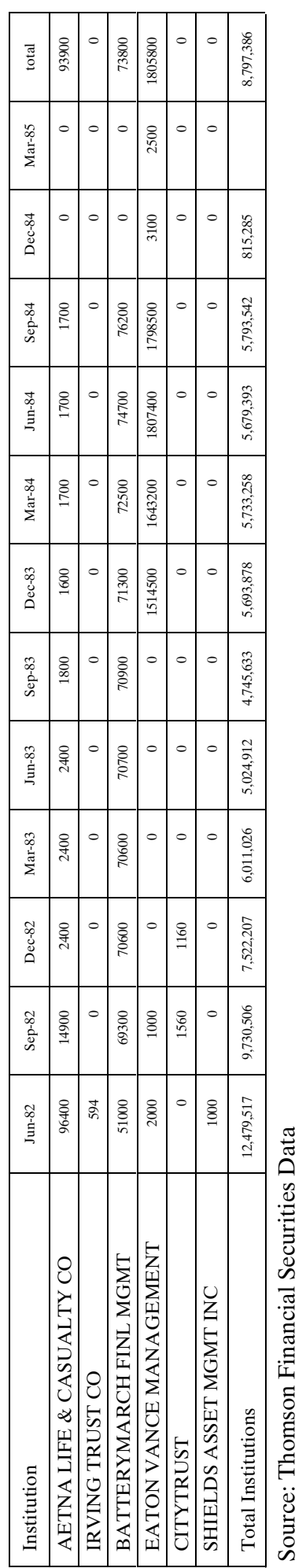


TABLE D

RATIO OF RETAINED SHARES FROM CLAIMS SUBMISSIONS TO THE RETAINED SHARES FROM THE GTM (1X) FOR MIDWESTERN

Retained Shares Estimated from GTM (1x) Corrected for Proper Adjustment of $60 \%$ of Reported Volume $1,880,000$

Retained Shares resulting from Claims Submissions (source: Cone and Laurence)

Ratio of Retained Shares from Claims Submission to Retained Shares from GTM (1x) 


\section{DATA FOR B AND C}

Total Float

$10,000,000$

Daily Volume

100,000

Days in Class period

25

\begin{tabular}{lcc} 
One Trader & Total & $\mathbf{1}$ \\
\hline Acceleration Factor & 1 & $99.00 \%$ \\
& & $1.010 \%$ \\
Damaged Shares & $2,221,786$ & $2,221,786$ \\
\hline
\end{tabular}

\begin{tabular}{cccc} 
Two Trader & Total & $\mathbf{1}$ & $\mathbf{2}$ \\
\hline Fraction of Float & $100 \%$ & $80 \%$ & $20 \%$ \\
Propensity to Trade & & 1 & 2 \\
Daily Volume & & 66,667 & 33,333 \\
& & $0.84 \%$ & $1.69 \%$ \\
Damaged Shares & $2,196,317$ & $1,510,176.73$ & $686,140.19$ \\
\hline
\end{tabular}

\begin{tabular}{cccc} 
Two Trader & Total & $\mathbf{1}$ & $\mathbf{2}$ \\
\hline Fraction of Float & $100 \%$ & $80 \%$ & $20 \%$ \\
Propensity to Trade & & 1 & 3 \\
Daily Volume & & 57,143 & 42,857 \\
& & $0.72 \%$ & $2.19 \%$ \\
Damaged Shares & $2,148,866$ & $1,312,572.27$ & $836,293.98$ \\
\hline
\end{tabular}

\begin{tabular}{cccc} 
Two Trader & Total & $\mathbf{1}$ & $\mathbf{2}$ \\
\hline Fraction of Float & $2882312670 \%$ & $80 \%$ & $20 \%$ \\
Propensity to Trade & & 1 & 4 \\
Daily Volume & & 50,000 & 50,000 \\
& & $0.63 \%$ & $2.56 \%$ \\
Damaged Shares & $2,098,541$ & $1,160,591.74$ & $937,948.96$ \\
\hline
\end{tabular}




\begin{tabular}{cccc} 
Two Trader & Total & $\mathbf{1}$ & $\mathbf{2}$ \\
\hline Fraction of Float & $765 \%$ & $80 \%$ & $20 \%$ \\
Propensity to Trade & & 1 & 5 \\
Daily Volume & & 44,444 & 55,556 \\
& & $0.56 \%$ & $2.86 \%$ \\
Damaged Shares & $2,051,161$ & $1,040,097.85$ & $1,011,063.09$ \\
\hline
\end{tabular}

\begin{tabular}{cccc} 
Two Trader & Total & $\mathbf{1}$ & $\mathbf{2}$ \\
\hline Fraction of Float & $1000 \%$ & $80 \%$ & $20 \%$ \\
Propensity to Trade & & 1 & 10 \\
Daily Volume & & 28,571 & 71,429 \\
& & $0.36 \%$ & $3.70 \%$ \\
Damaged Shares & $1,878,796$ & $684,495.44$ & $1,194,300.09$ \\
\hline
\end{tabular}

\begin{tabular}{cccc} 
Two Trader & Total & $\mathbf{1}$ & $\mathbf{2}$ \\
\hline Fraction of Float & $15741 \%$ & $80 \%$ & $20 \%$ \\
Propensity to Trade & & 1 & 15 \\
Daily Volume & & 21,053 & 78,947 \\
& & $0.26 \%$ & $4.11 \%$ \\
Damaged Shares & $1,779,288$ & $510,025.82$ & $1,269,262.00$ \\
\hline
\end{tabular}

\begin{tabular}{cccc} 
Two Trader & Total & $\mathbf{1}$ & $\mathbf{2}$ \\
\hline Fraction of Float & $55839 \%$ & $80 \%$ & $20 \%$ \\
Propensity to Trade & & 1 & 20 \\
Daily Volume & & 16,667 & 83,333 \\
& & $0.21 \%$ & $4.35 \%$ \\
Damaged Shares & $1,716,262$ & $406,414.49$ & $1,309,847.84$ \\
\hline
\end{tabular}

